\title{
Overview of modern applications of energy storage systems:
} part 2

This paper was downloaded from TechRxiv (https://www.techrxiv.org).

\section{LICENSE}

CC BY-NC-SA 4.0

SUBMISSION DATE / POSTED DATE

04-01-2021 / 08-02-2021

\section{CITATION}

Mihaylov, Vencislav; Kolev, Valentin; Stoilov, Dimo (2021): Overview of modern applications of energy storage systems: part 2. TechRxiv. Preprint. https://doi.org/10.36227/techrxiv.13516235

$\mathrm{DOI}$

10.36227/techrxiv.13516235 


\section{Overview of modern applications of energy storage systems: part II}

Vencislav Mihaylov

\section{ESO EAD}

Sofia, Bulgaria

vencivdm@abv.bg
Valentin Kolev

Faculty of Electrical Engineering

Technical University of Sofia

Sofia, Bulgaria

vkolev@tu-sofia.bg

\begin{abstract}
The use of Energy storage systems is becoming more widespread around the world due to the coincidental increase in available intermittent renewable energy. The main uses for energy storage are the balancing of supply and demand and increasing the reliability of the energy grid, while also offering other services, such as, cooling and heating for buildings and enabling the creation and use of portable electric devices and electric vehicles.
\end{abstract}

These technologies are divided into four main categories: thermal energy storage, electrochemical energy storage, mechanical energy storage, and chemical energy storage.

It has been shown in this study that Pumped Hydroelectric Energy Storage (PHES) currently is the most efficient form of energy storage and it is predicted that it will keep this position for the coming years as well. Technologies such as Lithium-Ion batters and heat storage have however also undergone significant improvements in recent years and might become viable substitutes for PHES. This study could not, however, define "best" and "worst" energy storage technologies, as each is has a specific use case in which they perform better than others.

\section{Keywords — power availability, reliability, energy storage}

\section{INTRODUCTION}

In a previous article [1], we presented the possible applications of energy storage systems. In this second part we analyze some of the specific competitive storage technologies.

Energy Storage Systems is the storage of different forms of energy over a period of time. New technologies provide efficient and environmentally friendly storing systems. We will categorise energy storage technologies by their output: electrical and thermal. Both types of outputs can be used to both generate and use each other as fuel, enabling symbiotic coupling in local heat transporation fuel and power markets. Energy storage technologies are a means of integrating system with the purpose of improving energy demand, management and supply. Often a singular storage device could be enough to severely improve the local energy services. Energy storage is also very attractive for balancing the load on the electrical grid. It can be used to minimize fluctuations in the frequency and thereby increasing the flexibility and reliability of the grid. The use of energy storages is especially useful in locations consisting of a large amount of renewable energy resources, like wind and solar arms, since it can enable the optimization of their production and have a more constant supply even though the renewable source is intermittent.

\author{
Dimo Stoilov \\ Technical University of Sofia; and \\ Institute for Nuclear Researches \\ and Nuclear Energy, BAS \\ Sofia, Bulgaria \\ dstoilov@tu-sofia.bg
}

\section{STATUS OF ENERGY STORAGE TECHNOLOGIES TODAY}

Multiple electricity and thermal storage technologies currently being researched and are in the R\&D stage of development and many other such technologies are already fully developed and being actively used. In the Technology Roadmap created by the IEA, there are in-depth descriptions and examples of many storage technology projects. "In Figure 1, some key technologies are displayed with respect to their associated initial capital investment requirements and technology risk versus their current phase of development (i.e. R\&D, demonstration and deployment, or commercialisation phases)" [20].

\section{Figure 1: Maturity of energy storage technologies [20].}

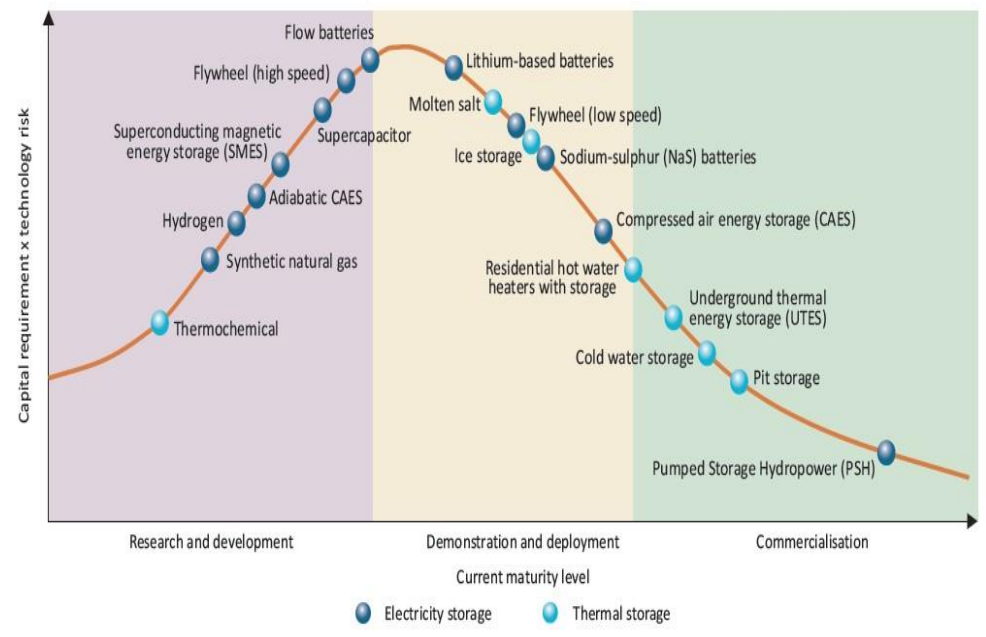

\section{CURRENT INSTALLED CAPACITY}

While there is some data available on the storage capabilities of modern energy systems, a full record of the total global energy capacity does not exist. Lack of widely available data and inconsistencies in definitions are to blame for the lack of such all-encompassing data.

"Today, it is somewhat easier to establish a baseline for some countries, including the United States and Japan as well as some regions in Europe, for a specific subset of energy storage technologies. In these cases, data can be found for large-scale, grid-connected electricity storage systems [21]. "These data reveal that at least 140 gigawatts (GW) of large-scale energy storage is currently installed in electricity grids worldwide. The vast majority (99\%) of this capacity is 
comprised of PSH technologies (Figure 2). The other 1\% includes a mix of battery, CAES, flywheels, and hydrogen storage" [21].

Remaining data gaps challenge attempts to establish a reliable baseline for current installed capacity and work in analysing future potential for both connected and off-grid systems. The potential of distributed energy storage in existing infrastructure has not yet been evaluated.

Figure 2: Current global installed grid-connected electricity storage capacity $(M W)$ [20].

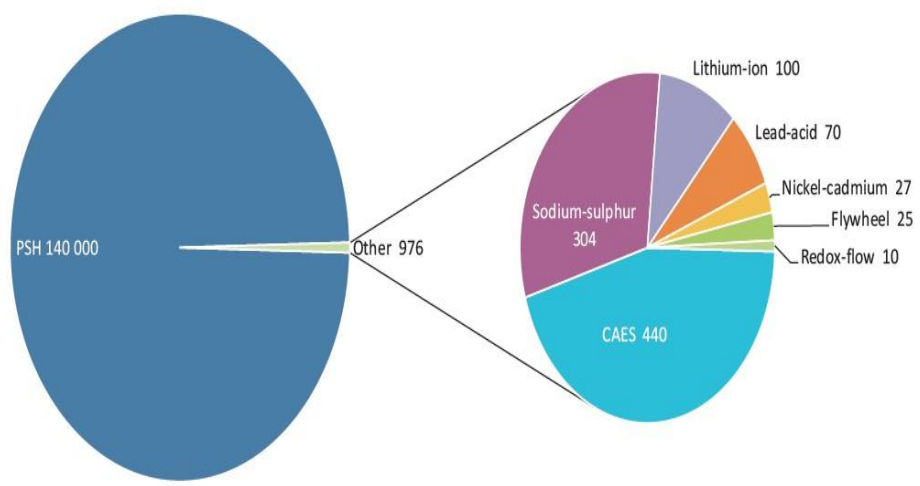

"For thermal energy storage, one of the most common technologies installed today is domestic hot water tanks. Other technologies, such as ice and chilled water storage, play an important role in in several countries, including Australia, the United States, China and Japan, as utilities seek to reduce peak loads and consumers seek to lower their electricity bills" [20]. "Underground thermal energy storage (UTES) systems are frequently found in Canada, Germany, and many other European countries" [12].

The IEA provided brief technology descriptions and examples of existing projects for both thermal and electricity storage technologies in their Energy Storage Technology Annex. "Table 1 depicts a range of energy storage solutions in terms of several technology characteristics. As these technologies cannot store and discharge energy without losses efficiency values are included in this table" [20].
"Table 1: Energy storage technologies: current status and typical locations in today's energy system*” [20].
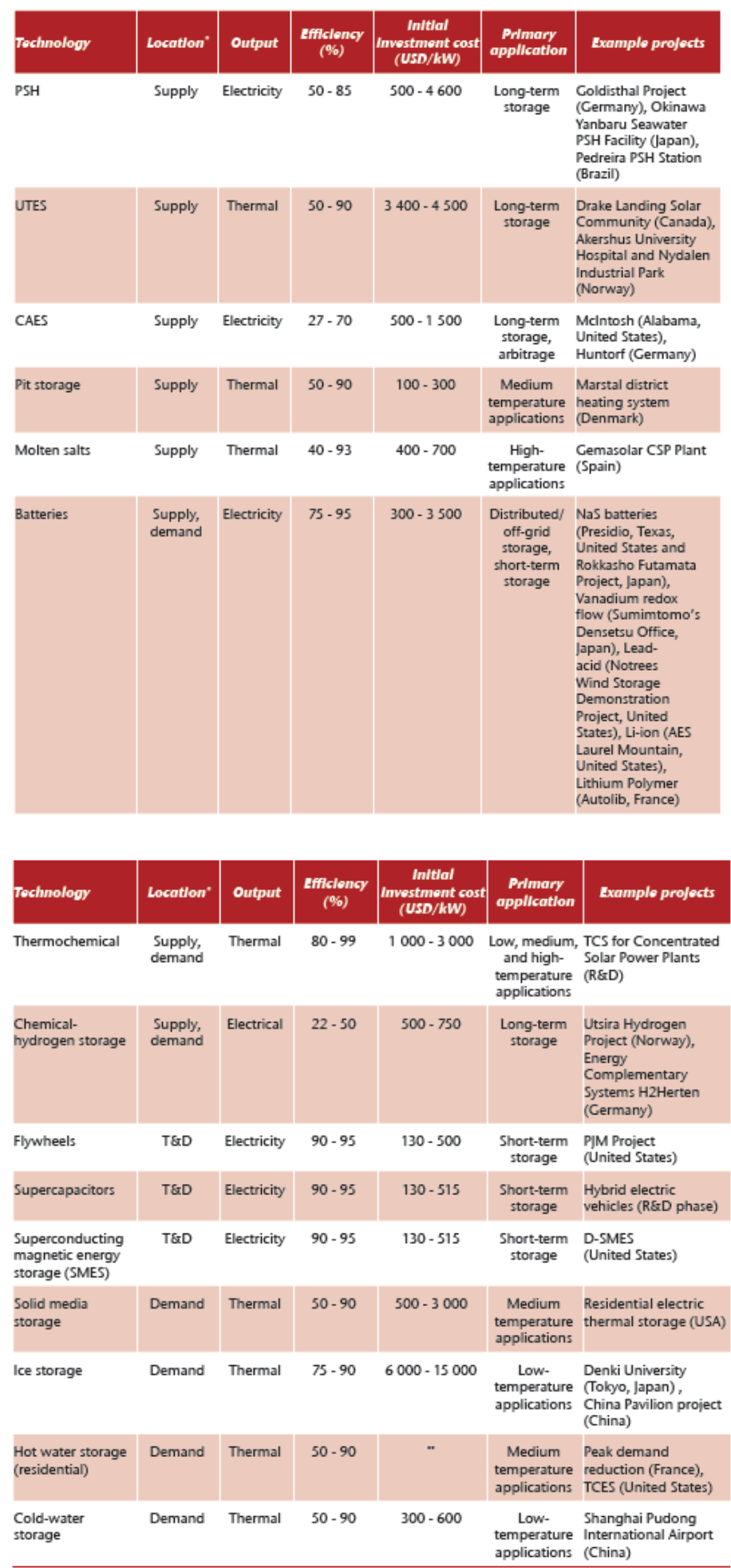

"* Typical locations in today's energy system. These locations may change as the energy system evolves" [20] 


\section{ELECTRICITY STORAGE}

The three main groups of electricity storage duration periods are short-term, long-term and distribution battery storage. CAES, PSH and a few other battery technologies currently the most thoroughly developed, while SMES, flow batteries and super capacitors are only in their development stage.

Hydrogen and battery technologies, amongst others, are currently receiving major R\&D investments in Japan, the United States and Germany. When developing new storage technologies, the operational and storage properties (including power and energy capacity, efficiency, density, discharge capacity, scale lifetime and response time) of these technologies are the main factors when assessing their usefulness.

\section{Short-term (seconds-minutes)} storage applications

"Supercapacitors and SMES Figure 3 technologies use static electric or magnetic fields to directly store electricity. Flywheels store Figure 4 and then release electricity from the grid by spinning and then applying torque to its rotor to slow rotation" [20]. "These technologies generally have high cycle lives and power densities, but much lower energy densities. This makes them best suited for supplying short bursts of electricity into the energy system. Modern technologies struggle in today's energy markets due to high costs relative to their market value" [20].

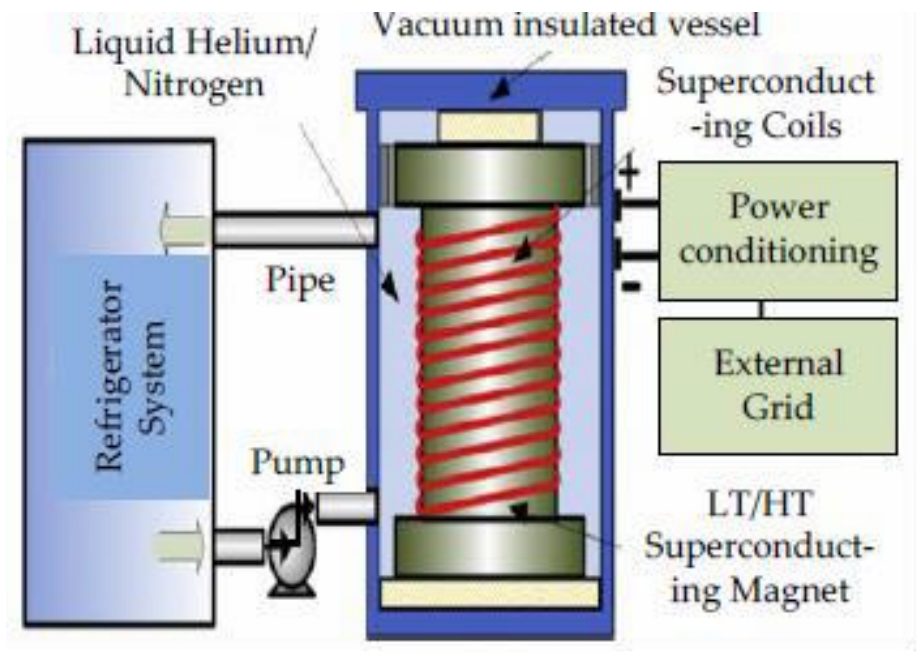

Figure3 . Schematic of superconducting magnetic energy storage (SMES)

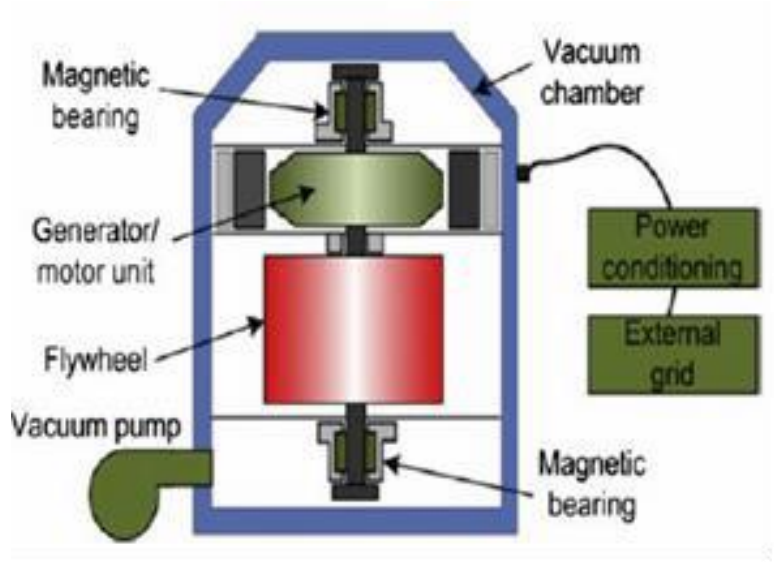

Figure 4. Schematic of a flywheel

\section{Distributed battery storage}

"Battery ESSs (BESSs) Figure 5 are categorised as electrochemical devices that deliver electric energy by conversion of chemical reactions. Power converters of BESSs are similar to those of wind turbines and photovoltaic (PV) systems; thus, they have an advantage in terms of flexibility" [20]. "BESSs can be classified as primary and secondary batteries. Primary batteries refer to non-rechargeable batteries, whereas secondary batteries refer to rechargeable batteries. However, only rechargeable batteries are utilised for power grid applications. Batteries were rarely used in early years due to their low energy density and short lifetime" [20]. "However, current advancements in batteries have attracted investors to install BESSs due to the high energy density and simple means of installations. Secondary batteries can be further classified into conventional and flow batteries. Conventional batteries are referred to as BESSs, whereas flow batteries are referred to separately" [20]. "BESSs, which are commonly used for current utility grid applications, are lead acid and lithium-based batteries. During discharging, electricity is generated through electrochemical processes. By contrast, electricity is converted into a chemical form by a reverse electrochemical process during charging" [20]. "Figure 6 obtained illustrates basic components of BESSs. BESSs consist of batteries, control, and a power conditioning system (C-PCS), whilst the remaining part comprises protection devices. BESSs have a wide range of applications due to the ease of installation and cost effectiveness" [20].

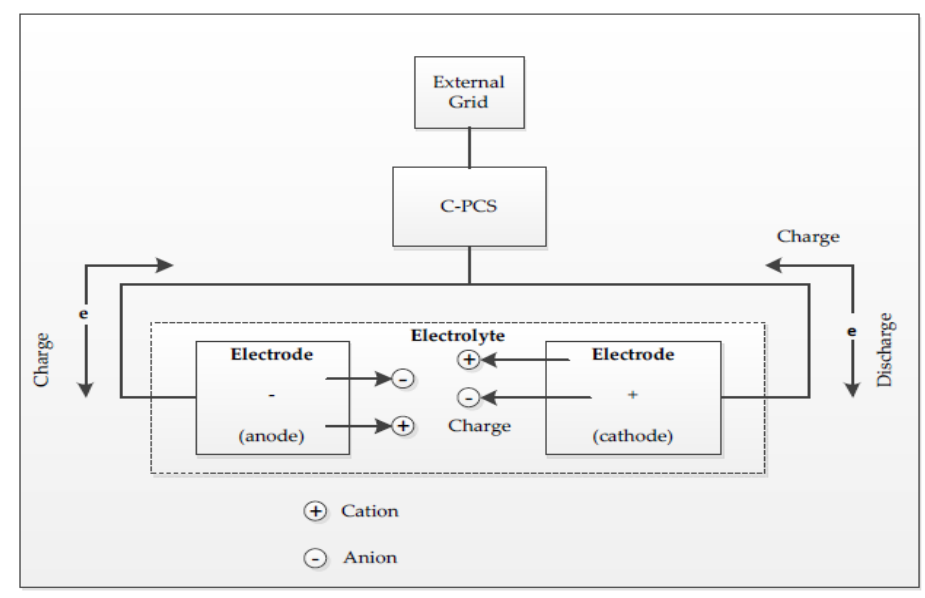

Figure 5. Schematic of a battery ESS (BESS) 


\section{Long-term (hours-seasons) storage applications}

"PSH Figure 6 are currently the most mature and widespread method for long-term electricity storage" [23] "In addition, two CAES Figure 7 facilities have been successfully used by utilities in the United States and Germany for several decades" [22]. "These technologies face high upfront investment costs due to typically large project sizes and low projected efficiencies for non-adiabatic CAES design proposals. In the case of pumped hydro and CAES, geographic requirements can lead to higher capital costs" [20].

"Today, there are two CAES systems in commercial operation, both of which use natural gas as their primary onsite fuel and are equipped with underground storage caverns. The larger of these two facilities is a $321 \mathrm{MW}$ system in Huntor f, Germany [21]. "Commissioned in 1978, this system uses two caverns (300 000 $\mathrm{m} 3)$ to provide up to 425 kilograms per second $(\mathrm{kg} / \mathrm{s})$ of compressed air (pressure up to 70 bars) produce efficiencies up to 55\%" [21]. "The other system, in McIntosh, Alabama, uses flue gas from its natural gas power plant for preheating to increase overall power plant efficiency" [21].

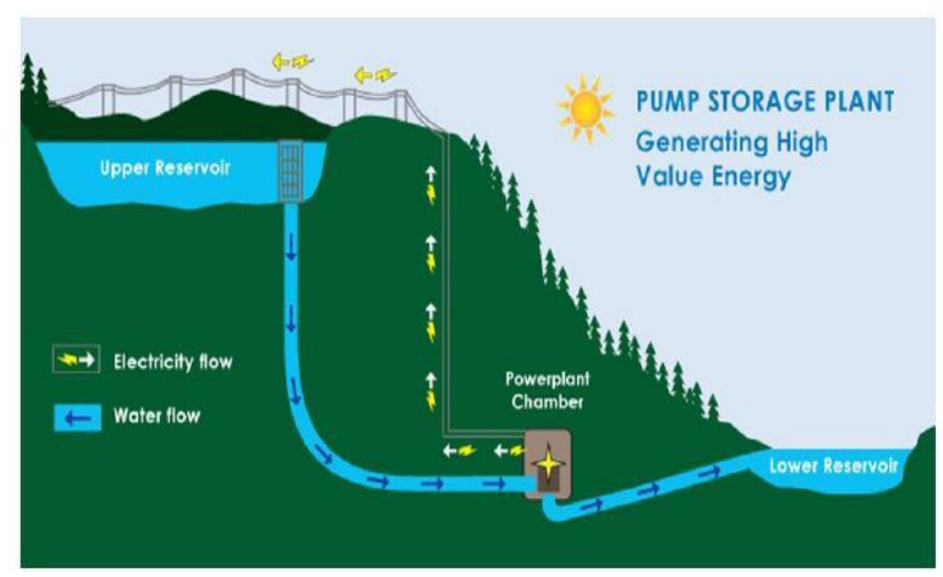

Figure 6. Configuration of a PSH



Figure 7. Schematic of compressed air energy storage (CAES).

\section{Hydrogen storage}

"Hydrogen storage Figure 8 can be used for long-term energy applications. Electricity is converted into hydrogen, stored, and then re-converted into the desired end- use form (e.g. electricity, heat, synthetic natural gas, pure hydrogen or liquid fuel)" [20]. "These storage technologies have significant potential due to their high energy density, quick response times, and potential for use in large-scale energy storage applications. However,

these technologies struggle with high upfront costs, low overall efficiencies and safety concerns, as well as a lack of existing infrastructure for large-scale applications" [20].

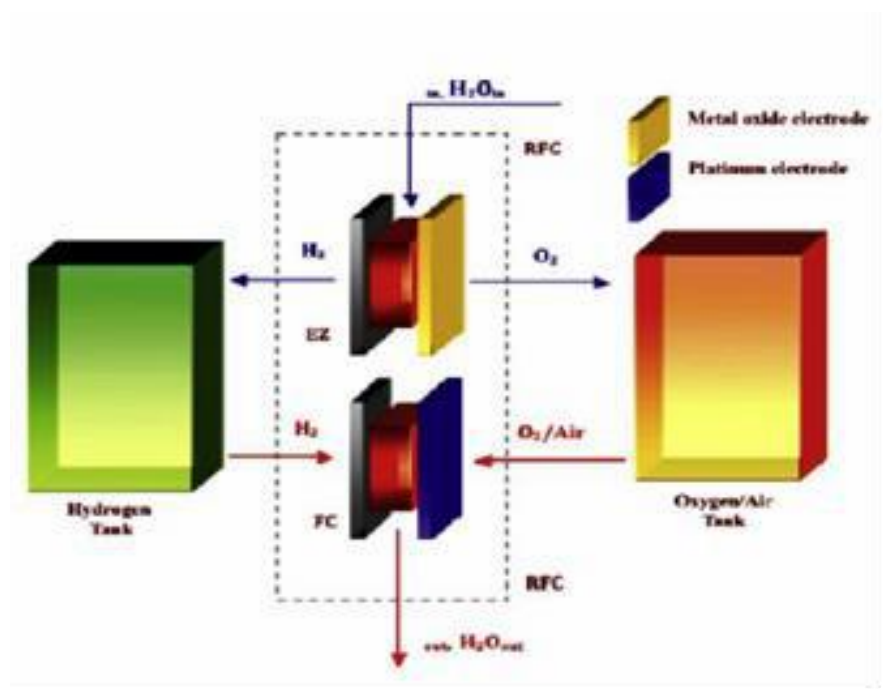

Figure 8. Configuration of a hydrogen-based fuel cell.:

All the illustrating figures presented here are from the informative publication of Development of Energy Storage Systems for Power Network Reliability: A Review [9].

\section{CONCLUSION}

Through this report it can be concluded that there is no optimal energy storage system for all applications, i.e. no single energy storage technology can be promoted as the only one to be further researched and developed. Instead, a combination of several types of energy storages is the best way forward. This is also the development which is seen in the world today, where several different countries invest in several different technologies.

As has been mentioned before, PHES is and will still be the largest energy storage technology, at least in terms of installed capacity, for many years to come. Other storage systems still have a long way to go before they can replace or be an alternative to PHES. PHES will most likely never be replaced but rather complemented with other systems. The alternatives which are undergoing the fastest development and are therefore very likely to be the most viable alternatives to PHES for large scale energy storage are the electrochemical energy storage systems, followed by sensible heat storage and possibly hydrogen energy storage. 


\section{REFERENCES}

[1] Mihaylov V., Kolev V., Stoilov D., Overview of modern applications of energy storage systems: part I, Science conference BulEF2020

[2] https://www.sciencedirect.com/topics/engineering/energy- storage-technology

[3] https://www.ucsusa.org/resources/how-energy-storage-works

[4] https://www.world-nuclear.org/information-library/current- and-futuregeneration/electricity-and-energy-storage.aspx

[5] https://energystorage.org/why-energy-storage/technologies/

[6] https://researchinterfaces.com/lithium-ion-batteries-gridenergy-storage/

[7] https://ease-storage.eu/energy-storage/technologies/

[8] https://www.sciencedirect.com/topics/engineering/energy- storage-system

[9] Development of Energy Storage Systems for Power Network

Reliability: A Review

[10] Decour t, B. and R. Debarre (2013), "Electricity storage", actbook, Schlumberger Business Consulting Energy Institute, Paris, France and Paksoy, H. (2013), "Thermal Energy Storage Today"

[11] IE A analysis and EPRI (Electric Power Research Institute) (2010), "Electrical Energy Storage Technology Options”, Report EPRI, Palo Alto, California

[12] IEA (2014a), Energy Technology Perspectives, for the coming, OECD/IEA, Paris, France. IEA (2011),

[13] Technology Roadmap: Energy Efficient Buildings: Heating and Cooling Equipment, OECD/IEA, Paris, France.
[14] Black \& Veatch (2012), "Cost and performance data for power generation technologies", Cost Report, Black \& Veatch, February.

[15] EPRI (Electric Power Research Institute) (2010), "Electrical Energy Storage Technology Options”, Report, EPRI, Palo Alto, California.

[16] Eyer, J. and G. Corey, (2010)" Energy Storage for the Electricity Grid: Benefits and Market Potential Assessment Guide", Sandia National Laboratory, Albuquerque, NM, United States.

[17] IEA- ETSAP and IRENA (2013), "Thermal Energy

Storage" Technology Brief E17, Bonn, Germany.

[18] IEA-ETSAP (Energy Technology Systems Analysis Programme) and IRENA (International Renewable Energy Agency) (2012), "Electricity Storage" Technology Policy Brief E18, Bonn, Germany.

[19] "Power Tower Technology Roadmap and Cost Reduction Plan", Sandia National Laboratories (2011), Albuquerque, NM and Livermore, CA, United States.

[20] International Energy Agency (IEA), "Technology Roadmap: Energy Storage," 2014. [Online].

Available:http://www.iea.org/publications/freepublications/publication/technolog y- roadmap -energy-storage

[21] Ying, 2011; US DOE, 2013

[22] Konidena, 2012

[23] 2015_ECES_26_final_report_public_rev16_web 